\title{
ANOMALOUS BEHAVIOUR OF ANTARCTIC ICE CORES STUDIED BY ELECTRICAL AND
}

\section{MECHANICAL DAMPING MEASUREMENTS}

by

\author{
R. Vassoille, J. Perez and J. Tatibouet,
}

(Groupe d'Etudes de Métallurgie Physique et de Physique des Matériaux, Institut National des Sciences Appliquées de Lyon, Bat. 502, 69621 Villeurbanne Cedex, France)

\section{P. Duval and M. Maccagnan}

(Laboratoire de Glaciologie et Géophysique de l'Environnement, 2 rue Très-Cloîtres, 38031 Grenoble Cedex, France)

\section{ABSTRACT}

In order to obtain new information concerning the anomalous properties of Antarctic ice previously observed through electrical measurements, we have studied specimens from a coastal site by means of internal friction measurements in the $1 \mathrm{~Hz}$ range. The results have been compared to previous ones obtained with polar ice from Dome $C$ and electrical measurements have been made on the same samples in order to confirm the anomalous behaviour of such material.

Two possible explanations of the anomalous properties of polar ice are discussed, namely the role of impurities and the ageing effect. It seems improbable that impurities could be responsible for such properties due to their low concentration. Some experiments, however, lead us to interpret the behaviour of polar ice in terms of modifications with time of the concentration and distribution of intrinsic point defects present at the beginning of the existence of the ice microcrystals.

\section{INTRODUCTION}

Previous work has shown that the electrical properties of polar glacier ice are very different from those of temperate glacier ice or pure laboratory ice. In geophysical resistivity surveys, Röthlisberger (1967) found that the electrical conductivity of cold polar glacier ice was orders of magnitude larger than that of temperate glacier ice. Dielectric properties of deep cores taken from polar glaciers have been studied by several authors (Paren 1973, Maeno 1974, Fitzgerald and Paren 1975, Maeno 1978). From these different studies, it was shown that relaxation times of the dielectric dispersion were shorter than those obtained with pure laboratory or temperate glacier ice. The activation energy of the principal relaxation time is around $0.23 \mathrm{eV}$ in polar ice compared with around $0.58 \mathrm{eV}$ in pure single crystals. Fitzgerald and Paren (1975) found that the electrical behaviour of polar ice is similar to that observed for single crystals doped with HF. It is difficult to explain the unusual electrical properties by impurity effects alone (Fitzgerald and others 1977). The most recent idea put forward was based on the influence of $\mathrm{CO}_{2}$ adsorbed at the ice surface (Paren and Glen 1978). This assumption seemed to be confirmed by a reported high $\mathrm{CO}_{2}$ content of polar ice. However, recent measurements have clearly shown that the $\mathrm{CO}_{2}$ content of polar ice is small compared with values given previously (Delmas and others 1980). By measuring the static electrical conductivity and the sulphate content of Dome $C$ and D 10 ice samples, Maccagnan and others (1981) found a relationship between the two studied parameters, but impurities did not seem to explain entirely the electrical properties of these samples. In other respects, internal friction measurements made in the $1 \mathrm{~Hz}$ range on ice from Dome $\mathrm{C}$ have shown that anelastic properties of polar ice, just like electrical properties, are very different from those of pure ice (Vassoille and others 1980). The aim of this paper is firstly to present the internal friction spectrum versus temperature of polar ice from $D 10$ (the relaxation phenomenon is observed at a particularly low temperature) and secondly to compare electrical and mechanical measurements made on the same polar ice.

2. EXPERIMENTAL METHODS

\subsection{Ice samples investigated}

Thermal core drifling to $906 \mathrm{~m}$ depth was carried out at Dome C, Antarctica (1at. $74^{\circ} 39^{\prime} \mathrm{S}$, 1ong. $124^{\circ} 10^{\prime} \mathrm{E}$ elevation $3240 \mathrm{~m}$ a.5.1., mean annual temperature $\left.-53.59^{\circ} \mathrm{C}\right)$ during the $1977-78$ Antarctic field season (Lorius and Donnou 1978). Below depths of $150 \mathrm{~m}$, many cracks were formed during the drilling operation. 010 is a coastal site near Dumont d'Urville (lat. $66^{\circ} 40^{\prime} \mathrm{S}$, long. $140^{\circ} 01^{\prime} \mathrm{E}$, elevation $270 \mathrm{~m}$ a.s.1., mean annual temperature $\left.-13^{\circ} \mathrm{C}\right)$. Thermal core drilling to bedrock ( $304 \mathrm{~m}$ ) was carried out in January 1974 (Gillet and others 1976). The two ice cores were kept at temperatures lower than $-15^{\circ} \mathrm{C}$ after the drilling operation. 


\subsection{Dielectric measurements}

The dielectric behaviour of ice samples $70 \mathrm{~mm}$ in diameter and about $7 \mathrm{~mm}$ in thickness were analysed in the range $50 \mathrm{~Hz}$ to $100 \mathrm{kHz}$. The equipment and procedures are described by Maccagnan and Duval (1982).

2.3 Internal friction of ice

It is now well known that ice exhibits mechanical damping or internal friction, i.e. energy is dissipated when a cyclic stress is applied to the material. This property is often characterized by the logarithmic decrement $\delta$ of free oscillations of a mechanical oscillating system in which the elastic element is the sample.

The internal friction of ice was first measured by Kneser and others (1955) and then studied in the $1 \mathrm{kHz}$ frequency range by Schiller (1958) and Kuroiwa (1964). More recent1y, low-frequency measurements (about $1 \mathrm{~Hz}$ ) have been made with the torsional pendulum technique (Vassoille and others 1974, Nakamura and Abe 1977).

In our laboratory, damping measurements are made on ice with a torsional pendulum either in the $1 \mathrm{~Hz}$ range (variations in the logarithmic decay of oscillations versus temperature are automatically recorded (Etienne and others 1975)) or in the $10^{-4}$ to $1 \mathrm{~Hz}$ range (forced-oscillation method (Etienne and others 1981)).

Specimens in the form of rectangular bars

( $8 \mathrm{~mm} \times 2 \mathrm{~mm} \times 76 \mathrm{~mm}$ ) were mechanically cut from the dritled ice core.

As ageing effects had been previously studied by maintaining pure ice crystals near the melting point (Tatibouet and others $1981[a]$ ) some annealing treatments have been made on polar jce in the same conditions; that is, by putting ice specimens in glass tubes which were immersed in a glycol bath maintained at a constant temperature of $271 \pm 0.5 \mathrm{~K}$.

\section{EXPERIMENTAL RESULTS}

Thirteen samples cut from blocks situated between depths of 126 and $900 \mathrm{~m}$ from Dome C were studied: as the results have been published elsewhere (Vassoille and others 1980), only one example of the anelastic properties of these samples is shown in Figure 1(a) (curve A). The features previously observed with lowfrequency internal friction measurements made on pure ice (Vassoille and others 1974) can again be seen: (i) in the high-temperature range, a peak associated with the movement of grain boundaries (Perez and others 1979), and (ii) at lower temperatures, a relaxation peak generally interpreted in tems of reorientation of water molecules by means of rotational defects (Vassoille and others 1978).

In the case of the former feature, no difference is observed between pure and polar ice; however, in the latter, the temperature $T_{p}$ of the relaxation peak in polar ice $(145 \mathrm{~K})$ is lower than in the case of pure ice ( 190 to $200 \mathrm{~K}$ at $1 \mathrm{~Hz}$ : curve B, Fig.1(a)).

To be sure that the preceding results are not caused by an experimental artefact, electrical measurements were also carried out. It is shown in Figure $1(D)$ that the variations of $\varepsilon^{\prime}$ and $\varepsilon^{\prime \prime}$ versus frequency of Dome $C$ ice core (curves A) are very different from those of pure ice (curves B).

To improve our knowledge of polar ice, other specimens have been studied. Thus, new results obtained on samples drilled from $D 10$ (46 m depth) have shown still larger differences from pure ice. In order to prevent any trouble connected with sample preparation, mechanical and electrical techniques have both been employed on the same specimens: the results are shown in Figure 2 . The relaxation phenomenon is observed at a lower temperature $(127 \mathrm{~K}$, Fig.2(a)) than in the case of Dome $C$ ice, and dielectric measurements confirm this low value of the relaxation time of the dominant dispersion (Fig.2(b)).

Actually, results concerning dielectric behaviour are more complex than those concerning internal
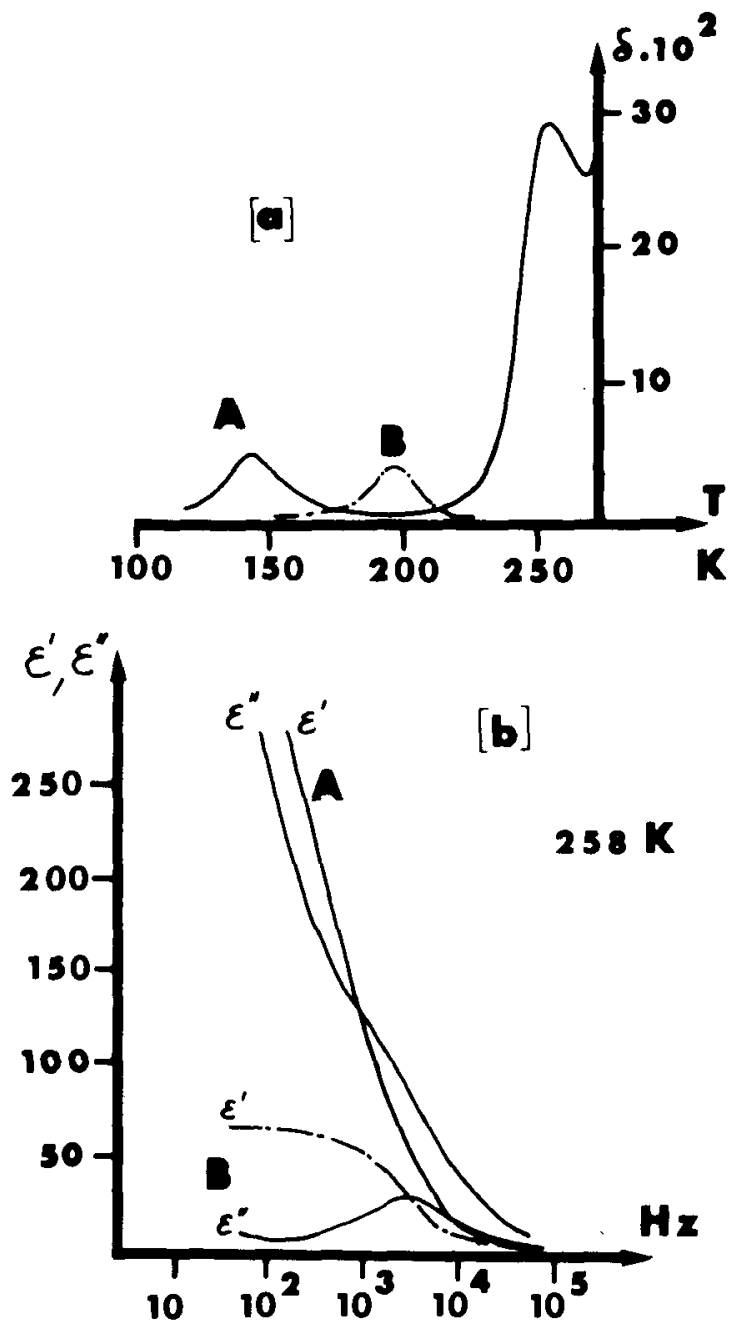

Fig.1(a). Internal-friction spectra versus temperature; curve A: specimen from Dome C $680 \mathrm{~m}$ deep, curve $B$ : pure ice.

(b). Real and imaginary parts of the permittivity $\varepsilon^{\prime}$ and $\varepsilon^{\prime \prime}$ versus frequency; curves $A$ : specimen from Dome $C 680 \mathrm{~m}$ deep, curves $B$ : pure ice.

friction as they are dependent on both relaxational effects and static electrical conductivity (SEC). For instance, the latter is higher in the case of Dome $C$ than in the case of D 10 ice (compare Figs.1(b) and 2 (b)). As this point has been discussed by Maccagnan and others (1981), more attention will be paid to the relaxation time. It is well known that a correlation does exist between the relaxation time for mechanical and dielectric relaxation: on the one hand, for a given temperature, mechanical and electrical relaxation times $\tau$ have nearly the same value, and, on the other hand, the temperature dependence of these relaxation times is similar.

Such a correlation has been experimentally verified by Kuroiwa (1964), but only in a frequency (temperature) range where the relaxational phenomenon in so-called pure ice is not sensitive to the extrinsic rotational defects. So it is interesting to note such a correlation at lower frequencies by comparing the results of Kawada (1978) on dielectric relaxational properties with the very recent results of Tatibouet and others (1981[b]) on internal friction of pure ice measured between $10^{-4}$ and $1 \mathrm{~Hz}$.

Figure 3 shows that the experimental points can be considered to lie along two straight fines: at high temperatures, the slope corresponds to $0.58 \mathrm{eV}$, implying rotational defects in thermodynamic equili- 


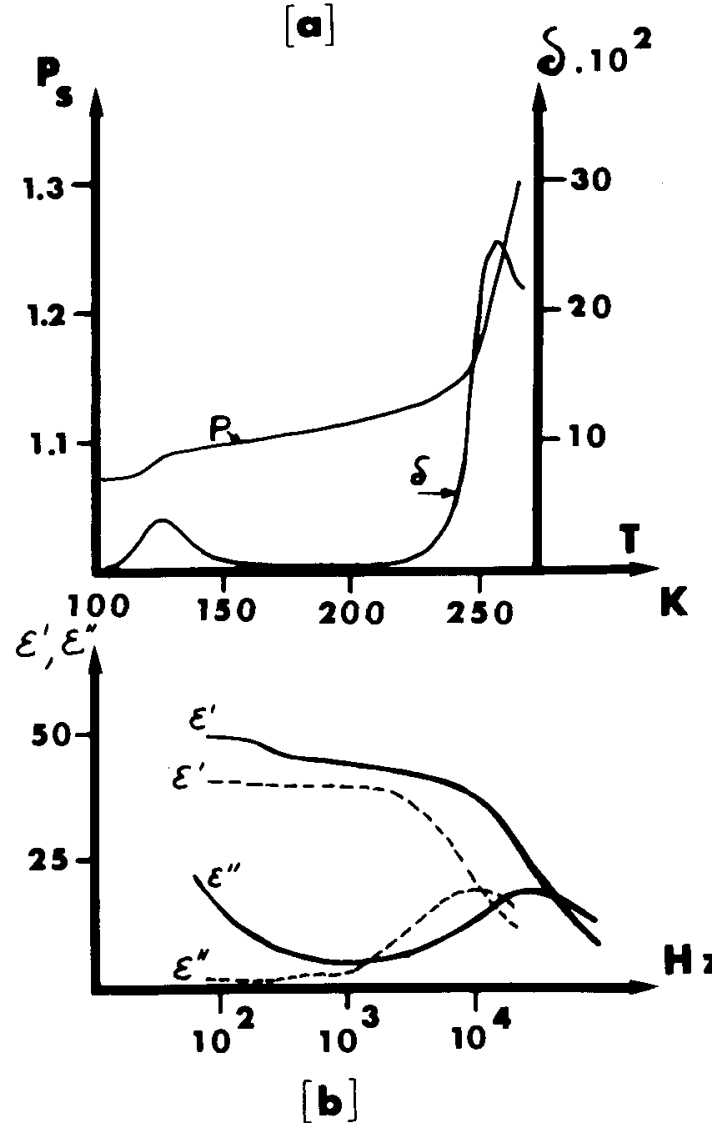

Fig.2. Comparison between mechanical and dielectric relaxation: specimen from $D 10$ station $46 \mathrm{~m}$ deep.

(a) Internal friction spectrum $(\zeta)$ and

period ( $P$ ) versus temperature.

(b) Permittivity $\varepsilon^{\prime}$ and $\varepsilon^{\prime \prime}$ versus frequency;

full line $T=258 \mathrm{~K}$, dashed 1 ine $T=230 \mathrm{~K}$.

brium; at low temperatures, the slope is $0.25 \mathrm{eV}$ (Tatibouet and others 1981[b]), implying rotational defects with a concentration independent of temperature. In the same figure, theoretical curves have been drawn from the simplified field relation

$$
\tau=\frac{\tau_{0} \exp \left(E_{M} / k T\right)}{C+\exp -\left(E_{F} / k T\right)},
$$

with $E_{F}=0.34 \mathrm{eV}$ and $E_{M}=0.24 \mathrm{eV}$ being the energy of formation and energy of migration of intrinsic rotational defects, respectively, and $C$ the concentration of extrinsic rotational defects.

As an example, an experimental point obtained from internal friction measurement made on ice doped with about $10^{-2} \%$ HF (Vassoille and others 1978) is also indicated.

Thus, by plotting the data obtained with polar ice in Figure 3 , it appears that such a material has a high content of rotational defects; an estimation of their concentration can be made leading to $5 \times 10^{-7}$ to $10^{-6}$ for ice samples from Dome $C$, and about $10^{-5}$ for ice samples from $D 10$.

\section{DISCUSSION}

First the effect of impurities and/or ice history will be specified and complementary experimental results presented. Then a tentative interpretation of the origin of the properties of ice from Antarctica will be proposed.

At first glance (see Figure 3 , for instance), the behaviour of Antarctic ice is very similar to that of laboratory-doped ice; the dielectric and mechani- cal relaxation peaks are observed at a low temperature as for HF-doped ice. So it may seem that impurities can explain all the experimental data concerning polar ice. However, chemical analysis does not support this assumption. The low value of $T_{p}$ would imply 0.5 to $1 \times 10^{-6}$ ionic impurity molecules giving rotational defects ( 30 to 60 ueql ${ }^{-1}$ ) with Dome $C$ samples, and about $10^{-5}$ with the $D 10$ sample $\left(600 \mu\right.$ eq $\left.\ell^{-1}\right)$. Actually, values about one order of magnitude lower have been published for central areas in Antarctica (Delmas and Boutron 1980, Delmas and others in press). D 10 samples have a sea-salt burden relatively high for an Antarctic ice sample, but not more than $0.5 \times 10^{-6}\left(32 \mu^{-1 e q \ell^{-1}}\right)$ of $\mathrm{Cl}^{-}$ (M Legrand personal communication). Thus, it does not seem possible to explain the low value of the relaxation time by extrinsic rotational defects.

Nevertheless, in the case of ice from Dome C, a good correlation between SEC and sulphate content has been observed (Maccagnan and others 1981). This point has been interpreted by making an assumption about continuous paths of liquid hydrated sulphuric acid in ice (Maccagnan unpublished).

The possibility that $\mathrm{CO}_{2}$ may be responsible has al so been considered ( $P$ aren and Glen 1978), but Delmas and others (1980) have now shown that the $\mathrm{CO}_{2}$

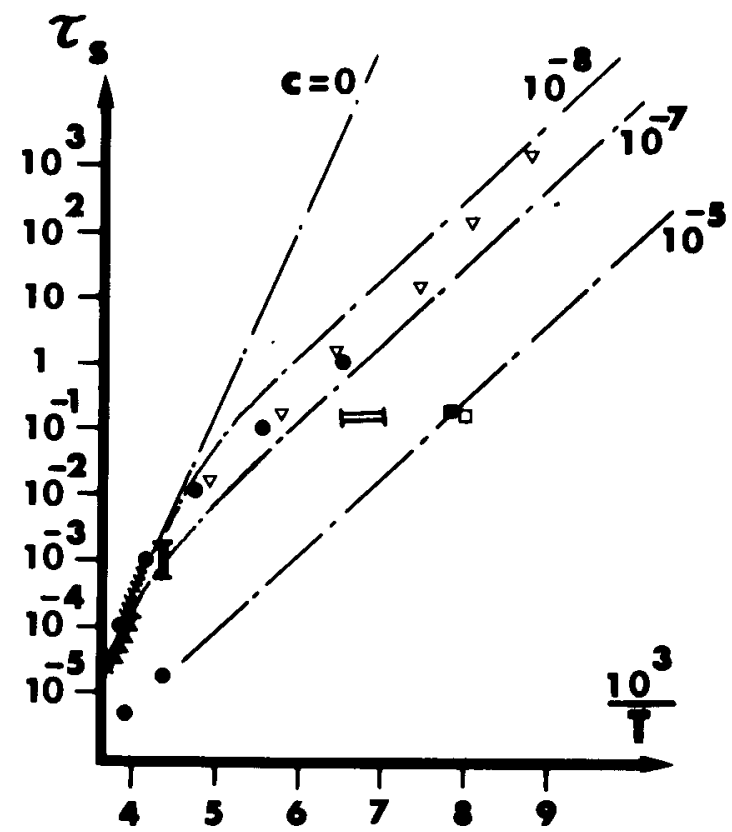

Fig.3. Relaxation time versus $T^{-1}$. $C$ is the concentration of impurities which leads to a rotational defect.

Mechanical relaxation:

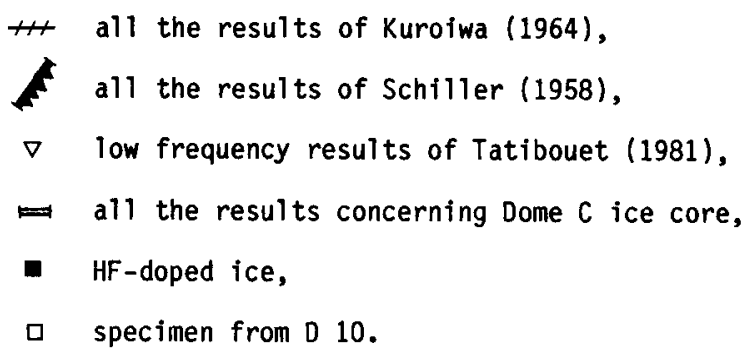

\section{Dielectric relaxation:}

$\oplus \quad$ specimen from 010 ,

I all the results concerning Dome $C$ ice core,

- from results of Kawada (1978). 
content in ice from Antarctica is lower than that previously anticipated, leading to a difficulty in attributing the anomalous properties of polar ice to the effect of $\mathrm{CO}_{2}$.

Intrinsic defects connected with the history of the material should be taken into consideration. Snow crystals are created by the freezing of super-cooled water and subsequently grow by diffusion of vapour and by coalescence processes. I ce sheets are formed through the sintering of such snow grains. I ce properties may therefore depend on (i) the conditions of crystal growth, i.e. climatic conditions, and (ii) ageing effects which probably occur in the first metres of the firn due to the high specific surface area presented by the material over an extended period.

In order to specify how the origin of the properties of polar ice may be better explained in terms of either impurity or intrinsic-defect effects, other experiments have been made (Vassoille and others 1980). These will be reviewed briefly. For example, a specimen of Dome $C$ ice (depth equal to $680 \mathrm{~m}$ ) has been melted and recrystallized. After recrystallization, the relaxation peak appeared in the same temperature range as for pure ice.

On the other hand, an annealing treatment at $270 \mathrm{~K}$ has brought all the specimens to the same structural state since $T_{p}$ was between 149 and $152 \mathrm{~K}$, as it was for artificial ice aged at $271 \mathrm{~K}$.

As the ice from $D 10$ seems to have a higher content of rotational defects, it was interesting to observe the effect of annealing at $271 \mathrm{~K}$. Indeed, after $1500 \mathrm{~h}$ at $271 \mathrm{~K}$, the peak has clearly shifted from 127 to $140 \mathrm{~K}$ as shown in Figure 4 . Such a result confirms that it is improbable that the anomalous properties of polar ice are induced by impurity effects. It seems easier to admit that the history of polar ice crystals implies that the formation of intrinsic defects in concentrations is higher than that of thermodynamic equilibrium in perfect crystals. Some fraction of these defects are then annealed when the material is kept at $271 \mathrm{~K}$.

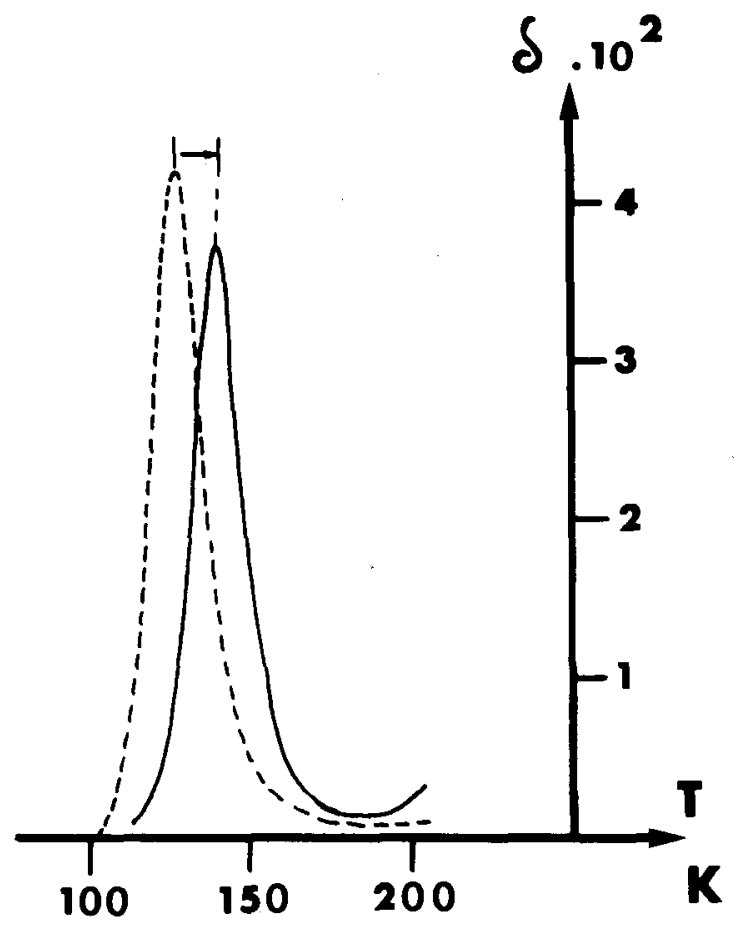

Fig.4. Internal friction spectra versus temperature of $D$ 10 sample. The relaxation peak has shifted from $127 \mathrm{~K}$ to $140 \mathrm{~K}$ after $1500 \mathrm{~h}$ at $271 \mathrm{~K}$.
Next, we compared the behaviour of Antarctic ice and that of aged ice studied by Tatibouet and others (1981[a]), who have shown that, during the ageing process, the microstructure is modified: in a freshiy grown single crystal a dislocation lattice can be observed by $X$-ray topography; during ageing, subgrains are formed and polygonization becomes more pronounced with increased duration of annealing at $271 \mathrm{~K}$. After about $1000 \mathrm{~h}$, the microstructurai state seems constant. So observations by $X$-ray topography have been made with ice from Dome $C$ : this material exhibits a fine microstructure which, in addition, varies with depth (Vassoille and others 1980).

The ageing phenomenon was interpreted by Tatibouet and others (1981[a]) in terms of a sort of disaggregation of the ice crystal in order to lower its free energy, assuming that internal stresses might exist in freshly grown ice crystals. These internal stresses can be relaxed by the creation of linear and point defects.

on the basis of these results (internal friction measurements and ageing studies), some ideas will be put forward to help to solve the problem. Anomalous properties of polar ice might be due to additional point defects induced by the ageing effect during the formation of ice crystals by transformation of snow. In the case of the ice from Dome $C$, the ageing temperature can rise to $250 \mathrm{~K}$ during summer in the first few metres of the firn, but is lower than $225 \mathrm{~K}$ between 10 and $900 \mathrm{~m}$ depth; nevertheless, $T_{p}$ is as 1 ow as 140 to $145 \mathrm{~K}$. With the ice from $D 10, T_{p}$ is still lower; however, the temperature of ageing may be higher. The specific area may not only increase the kinetics of ageing but may affect the "strength" of ageing, i.e. the smaller the size of the crystal, the more important the effect of ageing may be. Such an assumption implies that after growth of these small crystals the memory of the ageing effect is kept. This point remains to be clarified. To sum up, it seems possible that anomalous properties of polar ice are the consequence of the modification of the concentration and distribution of intrinsic defects through ageing phenomena connected with the conditions of formation of crystalline ice from snow.

\section{ACKNOWLEDGEMENTS}

Field work was supported by Terres Australes et Antarctiques Françaises, Expéditions Polaires Francaises, and the US National Science Foundation as a contribution to the International Antarctic Giaciological Project.

\section{REFERENCES}

Delmas R J, Boutron C 1980 Are the past variations of the stratospheric sulfate burden recorded in central Antarctic snow and ice layers? Joumaz of Geophysical Research 85(C10): 5645-5649

De1mas R J, Ascencio J-M, Legrand M 1980 Polar ice evidence that atmospheric $\mathrm{CO}_{2} 20,000 \mathrm{yr} B P$ was $50 \%$ of present. Nature 284(5752): 155-157

De1mas $R \mathrm{~J}$, Briat $M$, Legrand $M$ In press. Chemistry of south polar snow. Joumal of Geophysical Research

Etienne S, Perez J, Dubuisson B 1975 Estimation du coefficient d'amortissement en présence de perturbations. Application à la mesure du coefficient de frottement intérieur du matériau. Journal of Physics. Scientific Instruments 8: $666-670$

Etienne S, Cavaille J Y, Perez J, Salvia M 1981 Automatic system for micromechanical properties analysis. Joumal de Physique 42 Colloque $\mathrm{C5}$ supplement to No 10: $C-1129-C-1134$

Fitzgerald W J, Paren J G 1975 The dielectric properties of Antarctic ice. Journal of Glaciology 15(73): $39-48$ 
Fitzgerald W J, Glen J W, Paren J G 1977 Are the anomalous dielectric properties of polar ice due to impurities? International Association of Hydrological Sciences Publication 118 (General Assembly of Grenoble 1975 - Isotopes and Impurities in Snow and Ice): $3-8$

Gillet F, Donnou D, Ricou G 1976 A new electrothermal drill for coring in ice. In

Splettstoesser J F (ed) Ice-core drizing. Proceedings of a symposium, University of Nebraska, Lincoln... 1974. Lincoln and London, University of Nebraska Press: 19-27

Kawada S 1978 Dielectric anisotropy in ice Ih: Joumal of the Physical Society of Japan 44(6): $1881-1886$

Kneser H 0, Magun S, Ziegler G 1955 Mechanische Relaxation von einkristallinem $E$ is. Natumissenschaften 42(15): 437

Kuroiwa D 1964 Internal friction of ice. Contributions from the Institute of Low Temperature Science Ser A 18

Lorius C, Donnou D 1978 Campagne antarctique, novembre 1977 - février 1978. Centre National de la Recherche Scientifique. Courrier 30:6-16

liaccagnan M Unpublished. Contribution à 1 'Etude des proprietés dielectriques de la glace antarctique. (3rd cycle thesis, University of Grenoble, 1981)

Maccagnan M, Duval P 1982 Electrical behaviour of Antarctic ice and radio echo layers in ice sheets. Annals of Glaciology 3: 195-198

Maccagnan M, Barnola J M, Delmas R, Duval P 1981 Static electrical conductivity as an indicator of the sulfate content of polar ice cores. Geophysical Research Letters 8(9): 970-972

Maeno $N 1974$ Investigations of electrical properties of deep ice cores obtained by drilling in Antarctica. In Kuroiwa D (ed) Kyokuchi hyoshogori no butsuriteki kagakuteki kenkyu [Physical and chemical studies on ice from glaciers and ice sheets]. Sapporo, Hokkaido University, Institute of Low Temperature Science: $45-56$

Maeno $N 1978$ The electrical behaviors of Antarctic ice drilled at Mizuho station, East Antarctica. Memoirs of the National Institute of Polar Research. Special issue 10:77-94

Nakamura T, Abe 01977 Internal friction of snow and ice at low frequency. In Hasiguti $R R$, Mikoshiba $N$ (eds) Intermal friction and ultrasonic attenuation in solids. Proceedings of the sixth International Conference ... held 1977, Tokyo. Tokyo, University of Tokyo Press: 285-289

Paren J G 1973 The electrical behaviour of polar glaciers. In Whalley $E$, Jones $S \mathrm{~J}$, Gold $\mathrm{L} W$ (eds) Physics and Chemistry of Ice. Paper presented at the Symposium... 1972. Ottawa, Royal Society of Canada: 262-267

Paren J G, Glen J $W 1978$ Electrical behaviour of finely divided ice. Journal of Glaciology 21(85): 173-191

Perez J, Maï C, Tatibouet J, Vassoille R 1979 Etude des joints de grains dans la glace $I_{h}$ par mesure du frottement interieur. Physica status Solidi A 52: 321-330

Röthlisberger H 1967 Electrical resistivity measurements and soundings on glaciers: introductory remarks. Journal of Glaciology 6(47): 599-606

Schiller P 1958 Die mechanische Relaxation in reinen Eiseinkristallen. Zeitschrift für Physik 153: $1-15$

Tatibouet J, Mai C, Perez J, Vassoille R 1981 [a] Etude du vieillissement de la glace $I_{h}$ par mesures de frottement interieur et par observation en topographie aux rayons $X$. Joumal de Physique 42(10): 1473-1480

Tatibouet J, Perez J, Vassoille R 1981[b] Very low frequencies internal friction measuiements of ice $\mathrm{I}_{\mathrm{h}}$. Joumal de Physique 42 Colloque C5 supplement to No 10: $(-541-C-546$
Vassoille R, Tatibouet J, Perez J, Gobin P-F 1974 Comportement anélastique de la glace aux faibles frequences de sollicitation. Comptes rendus Hebdomadaires des Séances de l'Académie des Sciences Ser B 278(10): 409-412

vassoille R, Maï C, Perez J 1978 Inelastic behaviour of ice I s single crystals in the lowfrequency range due to dislocations. Journal of Glaciology 21(85): 375-384

Vassoille R, Ma $\mathrm{i} C$, Perez J, Tatibouet J, Duval P, Maccagnan M 1980 Anomalous behaviour of Dome $C$ ice core (East Antarctica) studied by mechanical damping measurements. Annales de Géophysique $36(4): 491-498$ 